\title{
UNIVERSITY DEPARTMENTS AND ENTREPRENEURIAL INTENTIONS: A CROSS-LEVEL ANALYSIS
}

\author{
SASCHA G. WALTER \\ Christian-Albrechts-University at Kiel \\ Kiel, 24118, Germany \\ Tel: +49431 8804378 \\ Fax: +49 4318803213 \\ Email: sascha.walter@bwl.uni-kiel.de \\ K. PRAVEEN PARBOTEEAH \\ University of Wisconsin - Whitewater \\ ACHIM WALTER \\ Christian-Albrechts-University at Kiel

\section{INTRODUCTION}

Offers of entrepreneurship programs and courses at universities have increased drastically in the last decade. But how effective are such initiatives? Prior research has focused either on individual-level factors, such as dispositions and family background, or on organizational-level factors, such as university quality and entrepreneurship education (Souitaris, Zerbinati, \& AlLaham, 2007). Both streams of research have evolved in relative isolation, whereas scholars of organizational behavior have suggested that behavior is ultimately determined by both dispositions and situations. To date, however, research bridging the gap between both levels to explain student and graduate entrepreneurship is still scarce. Our multilevel study addresses this gap by using data from 2,655 students and 389 professors at 65 university departments to examine the relationship of organizational-level factors (entrepreneurship education, entrepreneurship support programs, and industry ties) with students' entrepreneurial intentions, adjusted for critical individual-level factors (dispositions, role model performance, social network support, work experience, and opportunity perception). Building on human capital, network-based, and organizational norms research and learning style theory, we argue that the university setting can directly affect the likelihood that students identify and exploit opportunities, and thus their entrepreneurial intentions. Our approach spans levels of analysis thereby acknowledging the important but neglected influence of the organizational context on individual behavior, thus resolving some of the controversies in prior research. To policy makers and university managers, our findings may help to understand how effective current initiatives to stimulate academic entrepreneurship are. In particular, this knowledge can contribute to further improving such programs, also by considering their gender-specific outcomes.

\section{THEORETICAL DEVELOPMENT}

This multi-level study explores the impact of three organizational-level factors entrepreneurship education, entrepreneurship support programs, and industry ties - on students' entrepreneurial intentions, while controlling for short-run stable, individual-level factors. 
Entrepreneurship education refers to the scope of curricular lectures or courses aiming to sensitize and qualify students for an entrepreneurial career. It transfers entrepreneurship-specific human capital that can foster the recognition and development of business opportunities. Students learn about techniques to generate and evaluate elemental business ideas. Such prior knowledge can affect both the number and innovativeness of opportunities that they associate with the same technology. Entrepreneurship education can also increase the potential payoff from exploiting a given opportunity. It provides a basis in areas such as business planning, acquiring critical resources, and managing a new venture. Entrepreneurship students learn how to bring business ideas better or faster to market than others. Consequently, they should realize higher value from the same opportunity than others. Moreover, the number of courses indicates the degree to which entrepreneurial behavior is approved by a department. They signal social desirability, which was found to foster entrepreneurial intentions (Kolvereid, 1996).

Following suggestions in the literature, our analysis distinguishes two modes of education: (1) Active modes such as business plan seminars or simulations, where the student acquires knowledge through active experimentation, and (2) reflective modes such as theory lectures, where the student acquires knowledge through reflective observation. As we argue above, both modes should be positively related to entrepreneurial intentions. However, learning style theory suggests that (future) entrepreneurs should prefer active experimentation to reflective observation in acquiring critical knowledge (Kolb, 1976). Active modes increase the learning success because the higher involvement of students facilitates the knowledge transfer. Similarly, studies have shown that active modes rather than passive modes have greater chances of learning success (Gartner \& Vesper, 1994). In contrast, more reflective modes of education tend to require more passive participation from students and are also less directly applicable to exploiting entrepreneurial opportunities. This lack of practical relevance may therefore reduce the effectiveness of such educational opportunities. Thus,

Hypothesis 1a: The higher the extent of reflective modes of entrepreneurship education at a university department, the stronger the students' entrepreneurial intention.

Hypothesis 1b: The higher the extent of active modes of entrepreneurship education at a university department, the stronger the students' entrepreneurial intention.

Hypothesis 1c: Active modes of entrepreneurship education have a stronger effect on students' entrepreneurial intention than reflective modes.

Entrepreneurship support programs (e.g., SBIR in the US or EXIST in Germany) provide offers to sensitize, qualify, and support students for an entrepreneurial career. Lacking the initial personal network, students often have to rely on institutional network partners to overcome resource constraints that hinder or slow down the founding process. In the stage of opportunity development, such programs can give access to experts to evaluate elemental business ideas. Moreover, business plan competitions encourage students to further develop opportunities and offer contacts to mentors. This can demonstrate the value of an opportunity and, therefore, motivate students to exploit it through firm creation. In the stage of opportunity exploitation, students can receive extra-curricular training, for instance in venture financing or taxes, counseling, and, in some cases, obtain financial and non-financial support. Moreover, support programs may provide students with the necessary contacts, for instance to venture capitalists or 
to entrepreneurially minded peers, to facilitate opportunity exploitation. Such programs also signal that self-employment is socially desirable. In many countries, universities receive extra public funding to establish programs. Consequently, their existence reflects a public interest in academic entrepreneurship, whereas entrepreneurship education, as discussed earlier, reflects a university's interest in academic entrepreneurship. Thus,

Hypothesis 2: The more active entrepreneurship support programs at a university department, the stronger the students' entrepreneurial intention.

Industry ties measure the degree of industry partner activities at a university that can promote entrepreneurial behavior. Network-based research proposes that the number and nature of social ties influences the chances of opportunity recognition. Many entrepreneurs rely on informal industry contacts or participate in professional forums to learn about recent trends and developments (Ozgen \& Baron, 2007). For students, departments with intensive industry ties may thus prepare a better environment for entrepreneurship. In presentations and lectures, knowledgeable industry representatives provide information that can sensitize students to current market needs and assist them in identifying and developing opportunities. Students can use these contacts to learn about industry standards or to get referrals to potential investors, customers, or suppliers. Lectures and presentations by industry partners are a chance for potential entrepreneurs to establish direct social ties. In some cases, industry partners may also act as customers, suppliers, or even investors. Thus,

Hypothesis 3: The more intensive industry ties of a university department, the stronger the students' entrepreneurial intention.

\section{METHODS}

\section{Sample and procedures}

We drew a stratified random sample of 30 universities from the general population of 72 public universities in Germany. Within universities, we focused on three types of departments computer science, electrical engineering and business - because start-ups in these fields have a relatively high potential for growth and employment. Our study concentrates on university departments (or schools), rather than entire universities because departments and not universities define curricula and therefore control students' access to entrepreneurship education and students are more likely to interact within the sphere of their departments than across.

Individual-level data came from a survey of students at 65 university departments (23 in computer science, 17 in electrical engineering and 25 in business). To ensure that students had access to entrepreneurship offers and did not belong to any group with unique founding behavior, we retained respondents that had finished their second year of studies, had worked less than four years full time, were not likely to succeed a family business, were German citizens, and had not primarily selected their university for their entrepreneurship offers. Our final sample consisted of 703 female students and 1,952 male at 21 and 65 departments, respectively. Reflecting the usual distribution across studies, students from all three fields are represented in the male sample, whereas the female sample comprised only business students. Data on entrepreneurship support programs and industry ties came from a survey of full professors at the 
65 university departments, yielding a final sample of 389 professors (124, 133, and 132 respectively).

\section{Measures}

Dependent variable. Entrepreneurial intention refers to the subjective likelihood that a person becomes self-employed within five years of the successful completion of his or her studies. We focus on entrepreneurial intentions because they are measurable without unpredictable time lag, potential survival bias, an ex-post rationalization by the respondents, or the risk of identifying consequences instead of determinants of self-employment. Like all other items (unless stated otherwise), the 3-item construct was measured on a 7-point Likert-scale $(1=$ "I completely disagree", 7 = "I completely agree"; $\alpha=.81$ ).

Independent variables. We measure entrepreneurship education as the total number of credit points for curricular courses with entrepreneurship-specific content. Two researchers reviewed the curricula and coded course offers based on their descriptions independently into reflective and active modes. We operationalize entrepreneurship support programs as the extent of activities through which extra-departmental units attempt to promote entrepreneurial behavior at university departments, including five formative items for promotion, extracurricular training, business plan competitions, counseling, and material support. Professors rated the frequency of these activities (7-point Likert-scale, 1 = “seldom”, 7 = "often”). We measure industry ties as the level of activities of industry partners at university departments, including presentations held by industry partners and lectures held by industry partners. (7-point Likert-scale, $1=$ "seldom", 7 = “often”, $\alpha=.75)$.

Control variables. To measure need for achievement, we employed a five items-measure developed and validated in prior research. Need for independence was measured with four formative items, including the freedom to decide on working hours, work contents, work processes, and to operate without supervision. Risk-taking propensity was measured by a modified version of the established Risk Style Scale. Performance of entrepreneurial role models was measured with four formative items for the perceived entrepreneurial performance of parents, other relatives, friends, and acquaintances. Social network support, this is the extent of support expected for becoming self-employed after graduation, was measured on two dimensions (7-point Likert-scale, 1 = "no support”, 7 = "great support"; 4 formative items, respectively): sources of support (family, partner, friends, and acquaintances) and types of support (material support, procurement of contacts, information and good advice, emotional support). Workexperience was measured as the number of months as a wage-employee, including professional training and full time. Opportunity perception was measured with a dummy variable $(0=$ "no opportunity perceived”; 1 = “opportunity perceived”). To operationalize average student quality, we adopted a measure provided by the "Studentenspiegel” survey. Research budget was measured as the average budget granted by third parties per scientist.

\section{RESULTS}

Since our hypotheses evaluated main effects of variables at both levels on the individuallevel outcome, we used intercepts-as-outcomes models to test our hypotheses. All individuallevel predictors were centered around their group mean to prevent multicollinearity. Moreover, we estimated separate models for female and male students as the extant literature reported 
gender differences in venturing activities. Tests similar to ANOVAs by departments confirmed sufficient between-department variance for male students, but not for female students. However, to formally test our hypotheses, we conducted complete analyses for both genders. The organizational-level variables accounted for 29 percent in the between-department variance for both gender. The individual-level variables explained 23 and 21 percent of the variance in entrepreneurial intentions of women and men, respectively.

Hypotheses 1a and 1b posited a positive relationship between entrepreneurship education and students' entrepreneurial intentions. This hypothesis was only supported for male students and active modes of entrepreneurship education $\left(\gamma_{2}=.06, p<.01\right)$, thereby partly confirming Hypothesis 1c. Contrary to Hypothesis 2, we could find no significant link between entrepreneurship support programs and entrepreneurial intentions. We replicated this finding using (1) a dummy coded 1 for participation in the EXIST-program, Germany’s largest, nationwide program, and (2) additional university-level ranking data. Hypothesis 3, proposing a positive impact of industry ties, was supported only for male $\left(\gamma_{4}=.07, \mathrm{p}<.05\right)$, but not for female students. Among the controls, average student quality $\left(\gamma_{5}=-.11, \mathrm{p}<.05\right)$ and research budget $\left(\gamma_{6}=-.05, \mathrm{p}<.10\right)$ were negatively related the entrepreneurial intentions of females and males, respectively. With regard to our individual-level variables, the results are mixed. Regardless of gender, we found a positive relationship for entrepreneurial intentions with need for achievement $\left(\beta_{1 j}=.09, p<.05\right.$ for women; $\beta_{1 j}=.11, p<.001$ for men), role model performance $\left(\beta_{4 j}=.23, p<.001\right.$ for women; $\beta_{4 j}=.24, p<.001$ for men), and opportunity perception $\left(\beta_{7 j}=.35, p<.001 ; \beta_{7 j}=.27, p<.001\right)$. However, need for independence $\left(\beta_{2 j}=.08, p\right.$ $<.001)$, risk-taking propensity $\left(\beta_{3 j}=.09, p<.001\right)$, and social network support $\left(\beta_{5 j}=.04, p<.10\right)$ show a significant, positive impact only on the entrepreneurial intentions of male students. No significant effect was found for work experience.

\section{DISCUSSION AND IMPLICATIONS}

Results from our HLM models provide some gender-specific support for our premise that certain organizational-level factors foster students' entrepreneurial intentions, after controlling for individual-level influences. Significant findings for active modes of entrepreneurship education lend empirical support to a conventional conjecture. Thereby, we supplement prior, case-based evidence by surveying a representative, multi-university and cross-level sample. Moreover, results for industry ties suggest that intensive connections between the industry and university departments also inspire prospective entrepreneurs. Interestingly, women seem to be unaffected by these offers. One explanation is that other influences countervail the effect of organizational-level factors, such as an entrepreneurship community that is dominated by men may give female students few incentives to identify with that group and, ultimately, to pursue entrepreneurial careers. Possibly, current entrepreneurship promotion strategies are not adjusted to the specific needs of women entrepreneurs as their design might draw upon on the perceived male dominated notion of entrepreneurship.

The non-significant relationship of entrepreneurial intentions with reflective modes of entrepreneurship education was contrary to our hypothesis. One plausible explanation is that such courses require less involvement on the students' side and may therefore not encourage them to acquire additional knowledge or to intensively reflect on the idea of starting one's own venture. This result does not necessarily advocate to stop such courses because they still prepare students for entrepreneurship-related occupations, for instance as venture capitalist. In the 
ongoing debate about the teachability of entrepreneurship, future researchers might explicitly distinguish active and reflective modes. Moreover, we found no significant relationship between entrepreneurship support programs and entrepreneurial intentions. Thus, such offers do not seem to have a direct, motivational effect on students. One explanation is that influences within or above the organizational level neutralize the effect of such programs, for instance a negative image of entrepreneurs, a strong uncertainty avoidance within a society, or insufficient support by professors who are skeptical to the idea of academic entrepreneurship. Future longitudinal studies might examine whether such programs lead to a faster or better realization of existing intentions rather than fostering them at the outset.

Our study is not without limitations. First, data limitations preclude controlling for the actual participation in entrepreneurship classes. This limitation should not seriously handicap our investigation because the study demonstrates that offers of entrepreneurship courses explain a significant share of the between-department-variance in students' entrepreneurial intentions. Moreover, the pattern of our results did not change in several robustness checks. Second, our focus on organizational-level determinants led us to neglect regional influences. Third, we cannot predict how many students will actually realize their self-reported intentions and how many students will enter self-employment opportunity-driven, without intending it to date. Finally, our study was limited to the German context.

This paper provides some useful implications for the management of programs that encourage more academic entrepreneurship. First, an understanding of which modes of entrepreneurship education successfully raise the founding propensity of academics is important for such programs that need to optimally employ their scarce resources. Our finding that female students are unaffected by organizational-level factors might encourage program representatives to check whether their offers are adequately adjusted to the special needs of women entrepreneurs, for instance by providing female role models. Finally, detailed knowledge of which university settings are most responsive to entrepreneurship support is important for policy makers who have to make decisions about budgets. Our results suggest that academic entrepreneurs are more likely to come from universities with intensive industry ties than from other institutions. While our analysis provides initial insight into the effectiveness of several entrepreneurship resources, we hope that future studies will contribute to deepen our understanding of how universities can effectively promote academic entrepreneurship.

\section{REFERENCES}

Gartner, W. B. \& Vesper, K. H. 1994. Experiments in entrepreneurship education: Success and failures. Journal of Business Venturing, 9(3): 179-187.

Kolb, D. A. 1976. The learning style inventory: Technical manual. Boston: McBer \& Co.

Kolvereid, L. 1996. Prediction of employment status choice intentions. Entrepreneurship Theory \& Practice, 21(1): 47-57.

Ozgen, E. \& Baron, R. A. 2007. Social sources of information in opportunity recognition: Effects of mentors, industry networks, and professional forums. Journal of Business Venturing, 22(2): 174-192.

Souitaris, V., Zerbinati, S., \& Al-Laham, A. 2007. Do entrepreneurship programmes raise entrepreneurial intention of science and engineering students? The effect of learning, inspiration and resources. Journal of Business

Venturing, 22(4): 566-591. 